\title{
КРИМИНоЛОГИЯ
}

\section{К ВОПРОСУ О ПОНЯТИИ ПРЕСТУПНОСТИ ИНОСТРАНЦЕВ}

\section{Богомолова К.И.}

\begin{abstract}
Аннотация: Предметом исследования являются нормы действующего международного, федерального и регионального законодательства, статистические данные о состоянии преступности, связанной с иностраниами, материалы судебной и следственной практики, данные, полученные в результате анкетирования преступников-иностранцев и опросов экспертов, иные собранные автором эмпирические материалы, позволивщие установить криминологические особенности личности преступника-иностранца, личности жертвыиностранца; выявить факторы, обуславливающие совершение уголовно наказуемых деяний иностранцами и в отнотении их; разработать меры предупреждения данных преступлений. Методологической основой исследования служат современные методы познания, разработанные юридической наукой и апробированные практикой. Диссертационное исследование носит междисииплинарный характер, что обусловило выбор нескольких приоритетных методик при изучении преступности, связанной с иностранцами. Методологическую основу исследования наряду со всеобщим диалектическим методом познания при разработке понятийного аппарата и ключевых терминов по исследуемой проблеме составили иные общенаучные методы (анализ, синтез, системный подход, логические приемы индукиии и дедукиии). Правовая направленность исследования предопределила использование формально-юридического и сравнительно-правового методов. Кроме того, широкое применение в работе получили методы, выработанные криминологией, - опрос преступников-иностраниев, экспертный опрос сотрудников правоохранительных органов; изучение уголовных дел, анализ уголовно-правовой статистики. Научная новизна исследования определяется разработанной теоретико-криминологической моделью преступности, связанной с иностранцами, позволивщей определиться с состоянием, динамикой, тенденциями и криминогенными факторами данного вида преступности и выработать основные направления и конкретные меры его предупреждения.Впервые рассмотрен виктимологический аспект данной проблемы, что позволило автору внести предложения по совершенствованию мер виктимологической профилактики преступности, связанной с иностраниами.
\end{abstract}

Ключевые слова: Преступность, иностраниы, иностранные граждане, лица без гражданства, апатриды, виктимология, криминология, преступность иностранцев, подданыи, понятие. 
Понятие «иностранец» толкуется как гражданин, подданный другой страны [1]. Этот термин хотя и учитывает различие между гражданином (лицом, принадлежащим к постоянному населению республиканского государства, пользующимся его защитой и наделенным совокупностью политических и иных прав и обязанностей) и подданным (лицом, принадлежащим к постоянному населению монархического государства), является бытовым, а не юридическим. Между тем важно рассмотреть именно юридическое содержание этого понятия.

В «Юридическом энциклопедическом словаре» 1987 года к иностранным гражданам были отнесены лица, не являющиеся гражданами СССР и имеющие доказательства своей принадлежности к гражданству иностранных государств[2]. Данное определение воспроизводится в формулировке действующего Закона РФ от 25 июля 2002 г. «О правовом положении иностранных граждан в Российской Федерации»[3]. Целесообразно принять во внимание, что в нем учтено наличие монархической формы правления в ряде государств (например, в Великобритании) и указывается на институт подданства.

Существует и другое легальное определение рассматриваемого понятия. Оно дано в статье 3 Закона «О гражданстве Российской Федерации», в которой говорится: «Иностранный гражданин - лицо, не являющееся гражданином Российской Федерации и имеющее гражданство (подданство) иностранного государства»[4].

В юридической литературе термин «иностранец» имеет различное толкование. Ряд авторов трактуют термин «иностранец»как «иностранный гражданин» и «лицо без гражданства» другие полагают, что это лица, которые не являются гражданами данного государства или же не имеют гражданства ни одного государства. В юридической литературе понятие «иностранец» имеет неоднозначное толкование. Некоторые авторы, например, Л. Н. Галенская, В. Ф. Губин, трактуют термин «иностранец» как иностранный гражданин и лицо без гражданства. Под иностранным гражданином Л. Н.
Галенская подразумевает лицо, которое не является гражданином данного государства или же не имеет гражданства ни одного государства[5].

М.М. Богуславский и С.С. Гридин иностранцами считают как иностранных граждан, так и лиц без гражданства[6]. А.А. Рубанов под определением «иностранцы» подразумевает всех лиц, находящихся на территории какого-либо государства, не являющихся его гражданами и состоящими в гражданстве другого государства[7].

По мнению Т.Н. Кирилловой иностранцем является «лицо, имеющее постоянную политическую, экономическую и правовую связь с государством своего гражданства и находящееся во временной экономической и правовой связи с другими государствами»[8]. В данном случае напрашивается вывод, что постоянно проживающих в Российской Федерации иностранцев нельзя относить к этой категории, так как их экономическая и правовая связь с разным государством очень условна.

В некоторых работах иностранцами называют лиц, проживающих на территории СССР, не являющихся его гражданами и состоящих в гражданстве (подданстве) другого государства. Весьма близким к этому является и определение В.Д. Яворского: «Иностранец - это физическое лицо, постоянно или временно находящееся на территории Союза СССР, не являющееся советским гражданином и состоящее в гражданстве или подданстве другого государства»[9]. Здесь обязательным признаком иностранца считается его постоянное или временное нахождение на территории СССР.

По мнению Д.Д. Аверина, иностранцем в СССР считается лицо, находящееся под юрисдикцией Советского государства, не являющееся советским гражданином и состоящее в гражданстве или подданстве другого государства[10].

Приведенные дефиниции понятия «иностранный гражданин» нельзя признать безупречными:

Во-первых, иностранные граждане могут быть гражданами двух государств (бипатридами), иметь множественное гражданство, и в 
связи с этим возникает необходимость в уточнении формулировки в части указания на такую возможность. В самом деле, в теории государства и права бипатриды выделяются в качестве самостоятельных субъектов правоотношений наряду с иностранными гражданами[11], из чего можно сделать вывод (очевидно неправильный), что иностранцы не могут быть бипатридами и наоборот. Такая путаница, вызываемая неточностями в юридических определениях, конечно, нежелательна.

Во-вторых, иностранный гражданин обязательно должен иметь доказательства принадлежности к другому государству. Вполне допустимы ситуации, когда иностранный гражданин не может представить таких доказательств или по каким-либо причинам не желает их предоставлять. В этом случае он автоматически переходит в другую категорию - лиц без гражданства (апатридов). Поэтому определение, сформулированное в Законе «О правовом положении иностранных граждан в Российской Федерации», более точно, чем в Законе «О гражданстве Российской Федерации».

Таким образом, возникает необходимость в выработке единой дефиниции, в которой были бы, по возможности, учтены все указанные замечания. Однако прежде чем предложить соответствующее определение, необходимо дать его краткую содержательную характеристику. Она сводится к следующему:

1. Физическое лицо, имеющее гражданство иностранного государства и одновременно гражданство России, не относится к иностранцам, а считается (по гражданству) россиянином. В соответствии со ст. 62 Конституции гражданин Российской Федерации может иметь гражданство иностранного государства.

Гражданство - юридический факт, и оно порождает устойчивую правовую связь человека с государством, «выражающуюся в совокупности их взаимных прав и обязанностей», - говорится в преамбуле к Закону Российской Федерации «О гражданстве Российской Федерации». Эта связь должна выражаться, как минимум, в лояльности лица к государству, гражданином которого он является, чего вовсе не гарантирует состояние человека в двойном гражданстве. Затронутая проблема имеет непосредственное отношение к исследуемой нами теме. Возможны ситуации (вполне реальные), когда бипатрид осуществляет разведывательную деятельность (диверсии) в одной стране по заданию другой страны (будучи гражданином обеих). Ясно, что он будет выступать агентом, концентрирующим преступную активность иностранного государства.

2. Если гражданин Российской Федерации находится в определенной правовой связи с Россией, то такая связь вовсе не обязательна для иностранца, вопреки мнению Ю.В.Герасименко, полагающего, что иностранцем следует считать любое физическое лицо, которое, находясь в определенной правовой связи с российским государством, не является его гражданином и состоит в гражданстве (подданстве) иного государства[12]. Если довести мнение автора до логического конца, то следует прийти к абсурдному выводу, что иностранец, не имеющий правоотношений с российским государством, иностранцем вовсе и не является. Ю.В.Герасименко смешивает в данном случае вопрос о понятии иностранного гражданина с вопросом о правоотношениях, субъектом которых он выступает. Наконец, понятие «иностранец» не следует смешивать, как делают некоторые ученые, с понятием «лицо без гражданства». Так, М.М.Богуславский утверждал, что лица без гражданства вместе с иностранными гражданами составляют категорию иностранцев[13]. Действительно, в Конституции СССР 1977г. (ст. 37) и в Конституции РСФСР 1978г. (ст. 35) термин «иностранцы» использовался для собирательного обозначения двух категорий физических лиц: иностранных граждан и лиц без гражданства. Такой подход устарел, сейчас законодатель четко разделяет иностранных граждан (иностранцев) и лиц без гражданства.

Различие между иностранцами и лицами без гражданства в основном состоит в том, что иностранцы имеют юридическую связь с оте- 
чественным государством и это государство несет определенную ответственность за своего гражданина и обязано в случае возникновения необходимости прийти к нему на помощь. Что же касается лиц без гражданства, то единственным защитником их прав и свобод является государство места их пребывания. На это обстоятельство указывает Н.В. Витрук, который пишет: «Правовой статус гражданина и лица без гражданства всегда один: он определяется тем государством, гражданином которого данное лицо является или на территории которого лицо без гражданства проживает. Правовой статус иностранца по существу имеет двойной характер: это правовой статус гражданина конкретного государства и правовой статус собственно иностранца. Последний определяется тем государством, на территории которого данное лицо пребывает как иностранный гражданин»[14].

Правовой статус - это емкое понятие. Объем прав и обязанностей общего правового статуса регулируется почти всеми отраслями права. Исходя из особенностей общественных отношений, являющихся предметом регулирования каждой из отраслей права, допустимо говорить об отраслевом аспекте правового положения гражданина, в частности, гражданском, уголовном, уголовно-процессуальном и т.д. То же самое можно сказать и об иностранцах.

Изучение иностранных граждан для криминологов представляет интерес в связи с их противоправным поведением, а именно совершением ими преступлений. В настоящее время противоправное поведение среди данной категории граждан на территории нашей страны приобрело широкий масштаб, поэтому сегодня мы можем говорить не об отдельных совершенных иностранцами и в отношении них, уголовно-правовых деяниях, а о таком явлении как преступность.

Для более полного и точного понимания рассматриваемого нами вопроса необходимо подробно остановиться на определении такого феномена, как преступность иностранных граждан.
Основываясь на классическом определении преступности как относительно массового, исторически изменчивого социального явления, представляющего собой систему преступлений, совершенных на данной территории за определенный период времени, аналогичным образом можно определить и преступность среди иностранцев, уточнив только, что соответствующие деяния совершаются иностранными гражданами. Однако такой подход, как представляется, не вполне адекватен исследуемому феномену и не позволяет отразить реальную сложность изучаемого объекта, выразить его специфику, учесть внешние и внутренние взаимосвязи, определяющие как «фон», так и внутреннюю логику развития. Поэтому необходимо оговорить одно существенное обстоятельство.

Это обстоятельство, на наш взгляд, имеет отношение к такому определяющему свойству преступности, как системность. «Именно в результате того, что преступность представляет собой определенную систему взаимосвязанных элементов, она обладает относительной самостоятельностью, такими качественными характеристиками, которые не свойственны отдельным ее элементам», - пишет А.И. Долгова[15]. Системный характер преступности среди иностранцев выражается в том, что она вбирает в себя два принципиальных элемента: преступления иностранцев и преступления, совершаемые в отношении иностранцев. «Преступник и его жертва - иностранные граждане», - так можно обозначить названный феномен[16].

Выделение виктимологического аспекта и сопряжение его с собственно криминальным ракурсом существенно для преступности именно среди иностранцев по следующим причинам. Во-первых, иностранные граждане-преступники обычно становятся жертвами преступлений в силу плохого знания (или незнания) реальной обстановки, криминальных особенностей и понятий. Для иностранцев характерен, по терминологии Л.В. Франка, так называемый реверс - превращение преступника в жертву[17]. 
«Технология» большинства преступлений, совершаемых в отношении иностранных граждан в советское время, в период «застоя», когда страну посещали множество иностранных туристов, заключалась в том, чтобы спровоцировать иностранца на совершение преступления, а затем завладеть его имуществом путем обмана. На профессиональном сленге такое преступление называлось «разгон».

Во-вторых, иностранцы - жертвы преступлений, пытаясь восстановить справедливость, нередко сами становятся на преступный путь. Такая тенденция стала заметной в связи с появлением новой категории иностранцев - граждан независимых государств - бывших республик CCСР. Данная точка зрения подтверждена результатами проведенного нами анкетирования иностранных граждан, осужденных за совершение преступлений на территории РФ. Они не считают себя чужаками в России, скорее, привыкли чувствовать себя уверенно в новых экономических условиях. Криминальное пространство России для них не ново, поэтому они нетерпимо реагируют на противоправные действия в случаях, когда терпят от них ущерб. В этой связи нередко происходит двойная трансформация: преступник - жертва - преступник.

Системность преступности иностранцев вольно или невольно выделяется всеми исследо- вателями, которые рассматривают эту тему. Так, исследования О.Ю. Шадрина озаглавлена как раз с учетом отмеченного обстоятельства: «Методика расследования преступлений, совершаемых иностранными гражданами и в отношении граждан иностранных государств»[18].

Системность преступности, как отмечает один их первых исследователей этого феномена С.Е. Вицин, выражается в органической совокупности преступлений, связанных с преступной средой[19]. У преступников - иностранцев и жертв преступлений - иностранных граждан нередко одна и та же среда. Многие иностранцы приезжают в настоящее время в Россию, движимые корыстными интересами, стремлением «сделать бизнес», который в своей основе замешан, как правило, на обмане и злоупотреблении доверием. Криминальный характер современной предпринимательской деятельности в России, характерный для иностранных граждан, легко превращает их в жертвы преступных посягательств.

Следовательно, преступность среди иностранцев - это органическая совокупность (система) преступлений, совершаемых на территории Российской Федерации за определенный промежуток времени иностранцами и в отношении иностранных граждан и лиц без гражданства, объединенных общностью криминальной среды.

\section{Библиография:}

1. Ожегов С.И. Словарь русского языка. - М.: Русский язык, 1988. - С.2003

2. Юридический энциклопедический словарь. - М.: Сов. Энциклопедия, 1987. - С.159.

3. Закон Российской Федерации от 25 июля 2002 г №30 «О правовом положении иностранных граждан в Российской Федерации». С3 РФ 2002г. ст.3032

4. 4. Федерации». СЗ РФ 2002г. ст.2031.

5. Галенская Л.Н. Правовое положение иностранцев в СССР. М., 1962. С. 7.

6. Богуславский М. М., Гридин С. С. Статус иностранцев в СССР. М., 1984. С. 24.

7. Богуславский М.М., Рубанов А.А. Правовое положение иностранцев в СССР. М., 1962. С. 4

8. Кириллова Т.Н. Общее положение гражданской правосубъектности иностранцев в СССР // Правоведение. 1966, № 1. С. 105.

9. Яворский В.Д. Правовое положение иностранцев в СССР. Автореф. канд. дисс... Киев, 1977. С. 4.

10. Аверин Д. Д. Положение иностранцев в советском гражданском процессе. М., 1966. С. 25. 
11. Матузов Н.И. Правовые отношения // Теория государства и права: Курс лекций / Под ред. Н.И. Матузова, А.В. Малько. - Саратов, 1995. - С.396.

12. Богуславский М.М. Закон о правовом положении иностранных граждан в СССР // Советский ежегодник международного права. - М., 1982. - С.77.

13. Витрук Н. В. ОСм.: Криминология: Учебник для юридических вузов / Под ред. А.И. Долговой. - М.: ИНФРА-М. - НОРМА, 1997. - С. 76

14. Харитонов С.А. Преступность среди иностранцев. - Омск, 2000г. - С.32 См.: Франк Л.В. Преступник и его жертва. - Душанбе: Ирфон.

15. Герасименко Ю.В. Иностранцы: понятие и содержание их конституционно-правового статуса: Лекция. - Омск: Юридический институт МВД России, 1996. - С.7.

16. Богуславский М.М. Закон о правовом положении иностранных граждан в СССР // Советский ежегодник международного права. - М., 1982. - С.77.

17. Витрук Н. В. Основы теории правового положения личности в социалистическом обществе. М.: Наука, 1979. С. 162.

18. Криминология: Учебник для юридических вузов / Под ред. А.И. Долговой. - М.: ИНФРА-М. HOPMA, 1997. - C. 76

19. Франк Л.В. Преступник и его жертва. - Душанбе: Ирфон. 1978. - С.17.

20. Шадрин О.Ю. Методика расследования преступлений, совершаемых иностранными гражданами и в отношении граждан иностранных государств: (По материалам Дальневосточного региона). - Автореф.дис. канд.юрид.наук. - М.:Академия управления МВД России, 1998. - С.26.

21. Вицин С.Е. Системный подход и преступность. - М.: Академия МВД СССР.1980. - С.34.

22. Чирков Д.К., Антонов-Романовский Г.В., Литвинов А.А. Влияние миграционных потоков из-за рубежа на криминальную ситуацию в России // Национальная безопасность / nota bene. - 2013. - 3. - C. 511-515. DOI: 10.7256/2073-8560.2013.3.7627.

23. П.Н. Кобец Правовые основы противодействия деликтности в Москве с учетом территориальных различий и ряд приоритетных направлений ее предупреждения // Административное и муниципальное право. - 2011. - 12. - С. 57-64.

24. Кобец П.Н. О предупреждении преступлений - как сложном, многогранном процессе, обладающем определенными признаками целостности // Полицейская деятельность. - 2011. - 4. - С. 56-60.

25. Кобец П.Н. Краткая характеристика преступности в г. Москве в 2005-2010 гг. // Административное и муниципальное право. - 2011. - 5. - С. 5-9.

\section{References (transliterated):}

1. Ozhegov S.I. Slovar' russkogo yazyka. - M.: Russkii yazyk, 1988. - S.2003

2. Yuridicheskii entsiklopedicheskii slovar'. - M.: Sov. Entsiklopediya, 1987. - S.159.

3. Zakon Rossiiskoi Federatsii ot 25 iyulya $2002 \mathrm{~g}$ №30 «O pravovom polozhenii inostrannykh grazhdan v Rossiiskoi Federatsii». SZ RF 2002g. st.3032

4. Zakon Rossiiskoi Federatsii ot 31 maya 2002 g. №22«O grazhdanstve Rossiiskoi Federatsii». SZ RF 2002g. st.2031.

5. Galenskaya L.N. Pravovoe polozhenie inostrantsev v SSSR. M., 1962. S. 7.

6. Boguslavskii M. M., Gridin S. S. Status inostrantsev v SSSR. M., 1984. S. 24.

7. Boguslavskii M.M., Rubanov A.A. Pravovoe polozhenie inostrantsev v SSSR. M., 1962. S. 4 
8. Kirillova T.N. Obshchee polozhenie grazhdanskoi pravosub"ektnosti inostrantsev v SSSR // Pravovedenie. 1966, № 1. S. 105.

9. Yavorskii V.D. Pravovoe polozhenie inostrantsev v SSSR. Avtoref. kand. diss... Kiev, 1977. S. 4.

10. Averin D. D. Polozhenie inostrantsev v sovetskom grazhdanskom protsesse. M., 1966. S. 25.

11. Matuzov N.I. Pravovye otnosheniya // Teoriya gosudarstva i prava: Kurs lektsii / Pod red. N.I. Matuzova, A.V.Mal'ko. - Saratov, 1995. - S.396.

12. Boguslavskii M.M. Zakon o pravovom polozhenii inostrannykh grazhdan v SSSR // Sovetskii ezhegodnik mezhdunarodnogo prava. - M., 1982. - S.77.

13. Vitruk N. V. OSm.:Kriminologiya: Uchebnik dlya yuridicheskikh vuzov / Pod red. A.I. Dolgovoi. - M.: INFRA-M. - NORMA, 1997. - S. 76

14. Kharitonov S.A. Prestupnost' sredi inostrantsev. - Omsk, 2000g. - S.32 Sm.: Frank L.V. Prestupnik i ego zhertva. - Dushanbe:Irfon.

15. Gerasimenko Yu.V. Inostrantsy: ponyatie i soderzhanie ikh konstitutsionno-pravovogo statusa: Lektsiya. - Omsk: Yuridicheskii institut MVD Rossii, 1996. - S.7.

16. Boguslavskii M.M. Zakon o pravovom polozhenii inostrannykh grazhdan v SSSR // Sovetskii ezhegodnik mezhdunarodnogo prava. - M., 1982. - S.77.

17. Vitruk N. V. Osnovy teorii pravovogo polozheniya lichnosti v sotsialisticheskom obshchestve. M.: Nauka, 1979. S. 162.

18. Kriminologiya: Uchebnik dlya yuridicheskikh vuzov / Pod red. A.I. Dolgovoi. - M.: INFRA-M. NORMA, 1997. - S. 76

19. Frank L.V. Prestupnik i ego zhertva. - Dushanbe:Irfon. 1978. - S.17.

20. Shadrin O.Yu. Metodika rassledovaniya prestuplenii, sovershaemykh inostrannymi grazhdanami i v otnoshenii grazhdan inostrannykh gosudarstv: (Po materialam Dal'nevostochnogo regiona). - Avtoref. dis. kand.yurid.nauk. - M.:Akademiya upravleniya MVD Rossii, 1998. - S. 26.

21. Vitsin S.E. Sistemnyi podkhod i prestupnost'. - M.:Akademiya MVD SSSR.1980. - S.34.

22. Chirkov D.K., Antonov-Romanovskii G.V., Litvinov A.A. Vliyanie migratsionnykh potokov iz-za rubezha na kriminal'nuyu situatsiyu v Rossii // Natsional'naya bezopasnost' / nota bene. - 2013. - 3 . - C. 511-515. DOI: 10.7256/2073-8560.2013.3.7627.

23. P.N. Kobets Pravovye osnovy protivodeistviya deliktnosti v Moskve s uchetom territorial'nykh razlichii i ryad prioritetnykh napravlenii ee preduprezhdeniya // Administrativnoe i munitsipal'noe pravo. 2011. - 12. - C. 57-64.

24. Kobets P.N. O preduprezhdenii prestuplenii - kak slozhnom, mnogogrannom protsesse, obladayushchem opredelennymi priznakami tselostnosti // Politseiskaya deyatel'nost'. - 2011. - 4. - C. 56-60.

25. Kobets P.N. Kratkaya kharakteristika prestupnosti v g. Moskve v 2005-2010 gg. // Administrativnoe i munitsipal'noe pravo. - 2011. - 5. - C. 5-9. 